\title{
HIGHER-ORDER AWARENESS IN ALEXANDER OF APHRODISIAS
}

\section{VICTOR CASTON}

The opening lines of Alexander's De anima are bound to excite the modern reader. ${ }^{1} \mathrm{He}$ argues that in order to find fulfilment and live in accordance with nature, we must follow the Delphic maxim, 'Know Thyself'; and that such knowledge belongs to psychology, the subject of his treatise. We might easily be led to expect that self-knowledge, and with it the nature of the self and of consciousness, will be discussed from an Aristotelian perspective.

But in fact Alexander's reasoning runs on slightly different lines. In order to find fulfilment, his words make clear, we must have a clear understanding of what sort of thing we are, namely, humans; and we are human in virtue of our souls. So by learning about the soul, we learn what makes us human and what our fulfilment consists in (1.2-2.4). He is thus far from the tradition represented by Plato's First Alcibiades, which takes the Delphic maxim to be a quest to know our individual selves $(130 \mathrm{c}-\mathrm{e})$. He is closer to Socrates' understanding of the maxim in the Phaedrus, as the attempt to find out just what kind of thing he is, whether a monster like Typhon or something that has a share in the divine (229e230a); and closer still to a Peripatetic view, explicitly attributed to Antiochus of Ascalon, ${ }^{2}$ but presumably older, that spells the maxim out in terms of our nature and characteristic activity as human beings. Although this construal may seem strange to us, it is a natural development of an even older and more traditional way of taking the maxim, regarding our place and limits as human beings. One of Alexander's ultimate concerns in the De anima is our mortality, something he makes evident in the very first line, when he declares that he will speak only about the soul of a body that 'comes to be and perishes' ( $\pi \varepsilon p i$

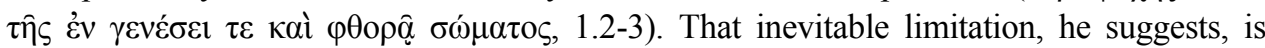
something Aristotelian psychology helps us to accept about ourselves, while at the same time allowing us to marvel at the amazing powers we have and the 'extraordinary magnificence of nature' ( Aristotelian science thus supports the traditional understanding of the Delphic maxim, by deepening our appreciation of mind's place in the world.

\footnotetext{
${ }^{1}$ This article is dedicated in the memory of Bob Sharples, with whom I read and studied the Alexander's De anima in graduate school. I learned immensely from his work and from his example. To my mind, he has done more of lasting value for Alexander than anyone else in the last one hundred years. I would also like to thank my audiences in London, Toronto, and Chicago for much valuable discussion, and especially Joel Yurdin, my commentator in Toronto.

${ }^{2}$ Cicero Fin. 5.44; cf. 5.26-7, 34.41; 4.25-6; also Aug. $C D 19.3$
}

BICS-55-1 - 2012

31

(C) 2012 Institute of Classical Studies University of London 
Does Alexander have anything of interest to say about consciousness or self-knowledge, then? I believe he does, though there is little of it in his own De anima. In the miscellany of puzzles and solutions known as the Quaestiones, there is an extended discussion of Aristotle's discussion in De anima 3.2 of perceiving that we perceive. Part of the interest of this passage is how Alexander develops what has subsequently become the mainstream reading of Aristotle's argument. But Alexander also makes a stronger and more interesting claim, about how this sort of higher-order awareness follows from Aristotle's other doctrines about perception and indeed cognition more generally. This stronger claim is more problematic, though, and it is hard to see how he can make good on it fully.

\section{Higher-order perceptual awareness}

Quaestiones 3.7 offers a detailed exegesis of the opening of De anima 3.2 (425b12-426a26), which at the same time develops Aristotle's points in distinctive and important ways. It follows the order of Aristotle's text so closely that it is easy to think of it as a draft for part of Alexander's lost commentary on the De anima (as distinct from his own treatise, likewise titled De anima), or perhaps a later rethinking of the passage. I will speak of its author as 'Alexander' for convenience, since it could conceivably have been written by someone else within his own circle, although in this case I fully expect that 'Alexander' is just Alexander.

The title and opening line of the quaestio frame the discussion of De anima 3.2 as primarily concerned with how sunaisthêsis comes about. The use of this term is already significant. For while sunaisthêsis and the cognate verb sunaisthanesthai do occur in Aristotle, they do not appear in De anima 3.2; and where they do occur, they are not used in the sense that they are used here (though they are not entirely unconnected either). ${ }^{3}$ What does Alexander mean, then, when he describes perceiving that we perceive as sunaisthêsis? In discussions of post-Aristotelian philosophers, including the Stoics and Alexander, sunaisthêsis is often rendered as 'self-awareness' or even 'consciousness."

${ }^{3} E N$ 9.9, 1170b4, 10; EE 7.12, 1244b25. On the notion of awareness in these passages, see L. A. Kosman, 'Aristotle on the desirability of friends', Ancient Philosophy 24 (2004) 135-54, who offers a brilliant reading of the complex and difficult argument of EE 7.12. He suggests that sunaisthêsis should be understood quite literally as a kind of joint or shared perception between two friends engaged in a common enterprise, to be contrasted with a kind of subjectivity inherent in our desire for life and experience (see esp. 147-54). For further (and more speculative) exploration of the ethical dimensions of the notion, see A. Flakne, 'Embodied and embedded: Friendship and the sunaisthetic self', Epoché 10 (2005) 37-63.

${ }^{4}$ Sharples uses 'self-awareness' in his translation of Quaest. 3.7 and in R. K. Sorabji, The philosophy of the commentators, 200-600 AD: A sourcebook, volume 1: Psychology (London 2004) 144-45. For a defence of this translation of the term, based on a broad survey of different terms for self-awareness in late antiquity, see R. K. Sorabji, 'Neoplatonist terminology drawn from the Stoics', in The philosophy of the commentators, 200-600 AD: A sourcebook, volume 1: Psychology (London 2004) 159-61. He argues that sunaisthêsis is 'very commonly used for self-awareness' by Plotinus and the commentators on Aristotle - this is, in fact, 'the commonest meaning' in Alexander and certain other commentators (p. 159) - and that this usage is based on earlier Stoic uses of the term, especially in Hierocles' Elementa moralia. On Neoplatonic usage specifically, see also M. Perkams, Selbstbewusstsein in der Spätantike: Die neuplatonischen Kommentare zu Aristoteles' 'De anima' (Berlin 2008) 337-41.

But while there are occasions where Alexander and the Stoics use the term sunaisthesis for awareness of our own psychological activity, I do not think this is the meaning of the term or even its commonest use, as I argue below at greater length for Alexander. Its most common use in these earlier periods is for awareness in the less theoretically freighted sense of noticing or being cognizant of and takes a wide range of objects, including external ones. (For a brief and very incomplete survey, see H. R. Schwyzer, 'Bewusst und unbewusst bei Plotin', in Les sources de Plotin, ed. E. R. Dodds, W. Theiler (Geneva 1957) 341-90 (355-60). Even where awareness of 
Against this tendency, however, I would argue that the term does not mean either of these things in Alexander, even if in a given passage (such as the present one) it should turn out that he is in fact referring to consciousness or self-awareness. The distinction is important, and not just methodologically. In approaching Alexander's remarks, we should initially keep open the question of whether he has consciousness specifically in mind. But even if he does, there is still a further more substantive question of precisely what he is claiming when he describes an activity as sunaisthêsis.

If we look at other occurrences of the term and its cognates in Alexander's corpus, there can be little doubt that the primary meaning of sunaisthêsis is simply:

the 'self' is at issue, it has to be understood in a fairly broad sense, and not a narrowly psychological one. In Hierocles, sunaisthêsis is used centrally for an animal's awareness of its own body, its strengths and weaknesses, and threats and opportunities in its environment, as the foundation for the Stoic doctrine of oikeiôsis: see G. Bastianini, A. A. Long, 'Hierocles: Elementa moralia', Corpus dei papiri filosofici greci e latini: vol. 1 (Florence 1992) 268-441 (2.1-3, 20, 23, 37-38; 4.57-58; 7.46-48). (Schwyzer, 'Bewusst und unbewusst' (above) 356 notes that sunaisthanesthai is in fact used frequently by late medical writers for awareness of one's own body.) In light of this, A. A. Long warns specifically against identifying sunaisthêsis in Hierocles with consciousness (A. A. Long, 'Hierocles and oikeiôsis and self-perception', in Stoic studies (Cambridge 1996) 250-63 (first publ. in A. A. Long, Hellenistic philosophy, ed. K. J. Boudouris, 2 vols (Cambridge 1993) I 93-104) (256, 260), despite his appeal to Nagel's notion of 'what it is like' to be a bat on p. 259, and likens it instead to proprioception: see Long, 'Hierocles and oikeiosis' (above) 258-59 and at greater length in Bastianini, Long, 'Elementa moralia' (above) 387-90; and more generally B. Inwood, 'Hierocles: Theory and argument in the second century AD', Oxford Studies in Ancient Philosophy 2, ed. J. Annas (Oxford 1984) 151-83. Vaguer references to sunaisthêsis, such as at Elem. mor. 3.55-56 should also be understood along the same lines, as should references to an animal's awareness of its self and its constitution in other discussions of oikeiôsis: Cic. Fin. 3.16 (=SVF 3.182); Sen. Ep. 121.5, 9, 12-13 (= SVF 3.184); Stob. Ecl. 2.7.3c, 2.47.13 Wachsmuth; and above all in the quotation from the first book of Chrysippus's De finibus

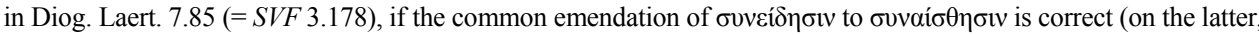
see Inwood, 'Hierocles: Theory' (above) 169, n. 19; and more critically Bastianini, Long, 'Elementa moralia' (above) 384). Similar remarks could be made about the Stoics' use of parakolouthêsis for an animal's awareness of its own movements, based on a broader, more ordinary notion of reflection: see the range of evidence listed in D. E Hahm, 'A neglected Stoic argument for human responsibility', Illinois Classical Studies 17 (1992) 23-48, esp. 36-39 and 44. When Epictetus uses the term for the awareness of the self, it is still used quite broadly, not for one's occurrent psychological state, but for an awareness of one's own character, ignorance, weaknesses, 1.2.30; 1.4.10; $2.11 .1 ; 2.21 .10$.

In saying that reflexive awareness of our psychological states is not part of the meaning of the term sunaisthêsis in earlier authors such as the Stoics, I am not claiming that they lacked such a notion or that they never used sunaisthêsis to express it. Galen quotes Chrysippus's use of the term in this way on at least two occasions: once, when we 'perceive, as it were', the various passions we are currently undergoing ( $\dot{\omega} \sigma \alpha v \varepsilon \dot{\mathrm{l}}$

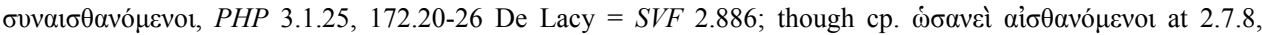
152.30-33 De Lacy = SVF 2.887), and again when we feel distress in our central governing power when we have a pain in our foot $(3.7 .4,212.14-18$ De Lacy $=S V F 2.900)$. But typically other expressions are used. Thus, Hierocles speaks of perceiving ourselves $(\dot{\varepsilon} \alpha v \tau \hat{\omega} v \alpha i \sigma \theta \alpha v o ́ \mu \varepsilon \theta \alpha)$ undergoing a corresponding qualitative change in our sense when we perceive external things which are white, sweet, or hot (6.1-10; Inwood, 'Hierocles: Theory' (above) 166, 177; Bastianini, Long, 'Elementa moralia' (above) 432-33); or of the reflexive character of

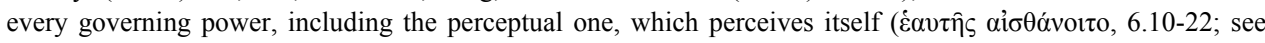
Inwood, 'Hierocles: Theory' (above) 166-67; Bastianini, Long, 'Elementa moralia' (above) 433-35). But the most important evidence for reflexive awareness, as Long points out (A. A. Long, 'Representation and the self in Stoicism', in Stoic studies (Cambridge 1996) 264-85 (first publ. in Psychology: Companions to ancient thought, vol. 2, ed. S. Everson (Cambridge 1991) 101-20) (271)), is surely the definition of representation (phantasia) in

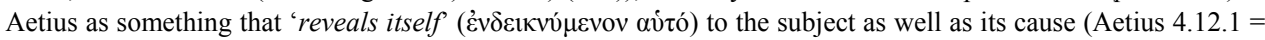
SVF $2.54=$ LS 39B; $c f$. Sext. Adv. Math. 7.161). 
(1) Being aware of something while perceiving something else.

As, in fact, its etymology would suggest $(\sigma \nu v+\sigma i \sigma \theta \eta \sigma l \varsigma)$. The most common cases involve cross-modal awareness of an object: for example, when we touch the hard, round surface of the brass sphere at the same time that we see its burnished golden colour, or when we see crossed fingers as one even though by touch we can feel that there are two. ${ }^{5}$ But Alexander also uses it for the awareness we have, while listening, of the distance of a sound, ${ }^{6}$ and of the resistance we sense when we make contact with an object. ${ }^{7}$ His only other uses of the term are for:

(2) The mutual sensitivity of one part of the body for another; 8

(3) The way in which self-evident principles are known to us 'from our own awareness'

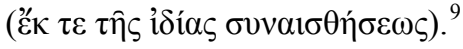

In none of these cases is awareness of the self or of mental states specifically at issue, even in (3). In the most common case, ${ }^{10}(1)$, there is only:

a. An awareness of the primary object (which belongs to perception proper);

$b$. An accompanying perception or awareness of something else.

Moreover, the object of this accompanying perception need not be part of our mental activity at all, as the examples above show, but rather a different feature of the external world. The translation of sunaisthêsis in (b) as 'accompanying perception' is simply for convenience and is not intended to prejudge any questions about the ontological analysis of such acts. In particular, it is not meant to imply that there is a distinct and separate act of perception, but only that in such cases we are perceiving something else in addition to the primary object of perception. It is meant to be neutral as to how this achieved.

The opening of Quaestiones 3.7 fits the same general pattern. Whenever we perceive something, we also perceive that we perceive - this second, higher-order perception accompanies the first. Alexander states that this second kind of perception accompanies every act of sense perception and explains the sense in which we are aware 'of ourselves':

When we perceive, we perceive ourselves, ${ }^{11}$ because anyone perceiving has, in

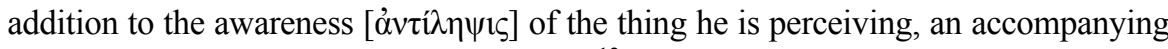

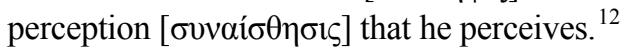

\footnotetext{
${ }^{5}$ In Metaph. 321.28-30; In Sens. 36.11-19; 163.11-16.

${ }^{6} \mathrm{DA}$ 50.18-20

${ }^{7}$ Mant. 130.22-24. This last case is somewhat complicated, as it involves consequences of an opponent's theory which he thinks conflict with our actual experiences: according to the Stoic theory of vision, we see by tensing the intervening pneuma and making contact with the object, like a blind person tapping objects with a stick; but if so, Alexander argues, we should also be aware of resistance when we strike the object, which we are not.

${ }^{8}$ In Metaph. 363.21-24; DA 15.15-17.

${ }^{9}$ In Metaph. 317.38-39.

${ }^{10}$ Contra Sorabji, 'Neoplatonist terminology' (n.4, above) 159.

${ }^{11}$ I accept Bruns's correction of the mss' $\alpha$ $\tau \hat{\omega} v$ to $\alpha \dot{\tau} \hat{\omega} v$ at 91.29 since the referent here can only be the subject of the sentence.
} 
Such perception does not require a concept of a self, or any conception of our selves individually. Indeed, it cannot, if Alexander's generalizations are to apply to all perceivers and all acts of sense perception, since on his view nonhuman animals perceive even though they are without understanding and so lack concepts. ${ }^{13}$ His point might be put as follows. When we perceive, the accompanying perception we have is not merely an awareness that perceiving is, so to speak, going on. Rather, we perceive with regard to ourselves that we are perceiving: in short, we have an essentially de se attitude, which is perceptual in character, regarding our perceptions of first-order objects. So we are not merely aware of the fact that we are perceiving, ${ }^{14}$ but of ourselves doing it.

Elsewhere Alexander adds that while we perceive, we are aware continuously of our perceiving and existing, without even the briefest interruption. If certain temporal durations could not be perceived, he argues:

... it would follow that during that time someone will fail to notice that he is perceiving and that he exists and will not perceive himself existing, so that during a period in which he perceives himself perceiving, he would not perceive himself either existing or perceiving. But this is impossible. For everyone, when he

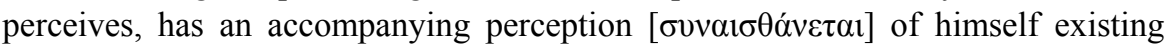
and perceiving. ${ }^{15}$

The higher-order perception in question, then, is an on-going activity, much like the firstorder perceptual awareness it accompanies. It is an awareness or experience of something rather than a mere judgement or acceptance of a fact.

Later in Quaestiones 3.7, Alexander is more specific about the content of this higherorder perception. We are aware not merely of ourselves perceiving, but of our perceiving the particular first-order objects we happen to perceive on that occasion. In fact, he claims that this sort of higher-order perception necessarily includes awareness of these objects:

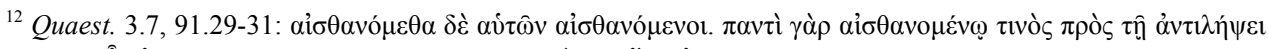

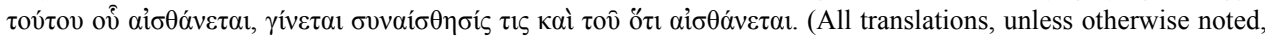
are my own.) For a parallel, see also his $D A 65.3$.

${ }^{13}$ Although Quaestiones 3.7 does not address the issue of nonhuman animals explicitly, it does state its

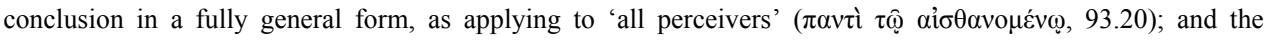
grounds he offers in support of this conclusion are equally general, turning on the nature of perception itself (92.31-93.20). Elsewhere, he takes the standard Aristotelian line that humans are the only animals that possess understanding, while all animals perceive ( $D A 30.10-15)$. Aristotle makes this denial in a number of places: see

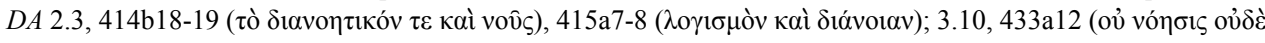

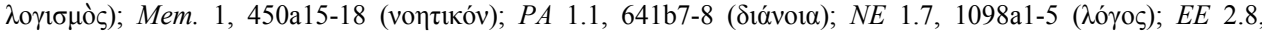

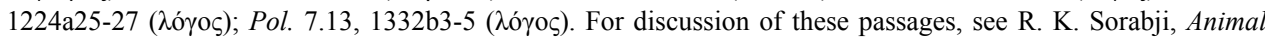
minds and human morals: The origins of the Western debate, Cornell Studies in Classical Philology - Townsend Lectures, vol. 54 (Ithaca 1993) 12, 14, 32-34, 38-39, 54-55.

${ }^{14}$ As Bob Sharples's translation of 90.30-31 might suggest.

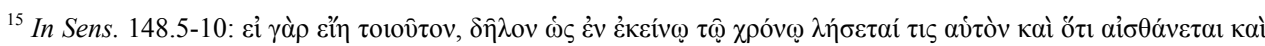

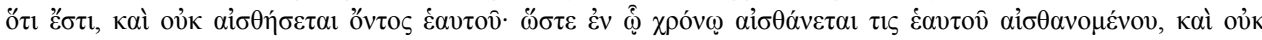

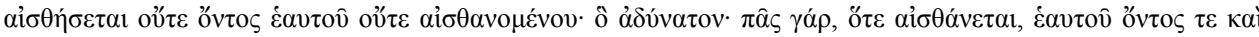

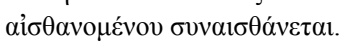


... so the [sense] that perceives the seeing will at the same time be a [sense] that perceives the colours as well. For the [sense] that perceives the occurrent activity concerning perceptibles would also perceive the things the visual activity concerns, namely, colours. For seeing is nothing but engaging in activity with sight concerning objects that can be seen, so that the perception of seeing is a perception of the occurrent activity concerning objects that can be seen by the visual sense. It is not possible to have a perception of the activity concerning specific things, without our perceiving those very things that the occurrent activity concerns. ${ }^{16}$

Alexander assumes, additionally, that the second-order perception is not of first-order

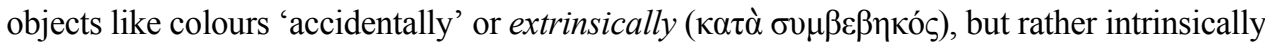

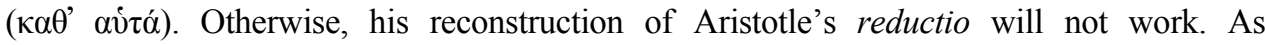
Alexander understands it (see below, pp. 39-40), Aristotle begins from an initial dilemma about the number of capacities involved in this kind of higher-order perception, such as when we perceive that we see. If it occurred through some capacity other than sight, there would be two different types of perceptual capacity that perceive colour; and that, Alexander

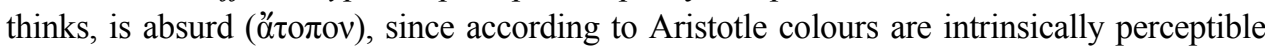
to sight exclusively ( $\tau \dot{\alpha}$ ídı,, $92.12-13$ ). But this last claim is contradicted only if colours were intrinsically perceived by another sense. Aristotle is explicit on this point: something that is intrinsically perceptible to one sense exclusively can nevertheless be perceived extrinsically by each of the other four senses (DA 3.1, 425a30-b2). So when Alexander argues that this higher-order perception must also be a perception of the first-order objects and therefore cannot be carried out by a different sense, he assumes that the first-order objects are intrinsically perceived in this higher-order perception.

But what about Alexander's initial claim, that the higher-order perception must inevitably be a perception of the first-order objects as well? The argument he offers gives us little reason to accept it. The key part of the inference (92.6-8) runs as follows:

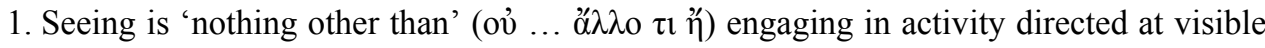
objects with sight.

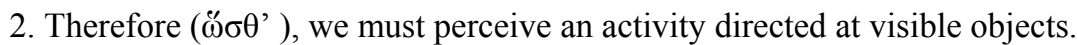

The inference turns on the essence of seeing, on what it is to see: to perceive our seeing as such, we must perceive it as an activity directed at visible objects. This seems entirely reasonable. But it will not get us to his conclusion, that we cannot perceive an activity

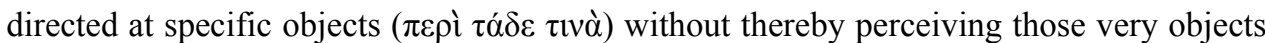
$(\tau \hat{\omega} v \delta \varepsilon)$. Imagine that the activity of seeing were itself intrinsically perceptible (something which has not been ruled out so far), and that we perceived it as something directed at first-order objects. It does not thereby follow that we would perceive the first-order objects themselves. Even if we helped ourselves to Aristotle's doctrine that the activity of perception is 'one and the same' as the activity of the first-order object - a doctrine that

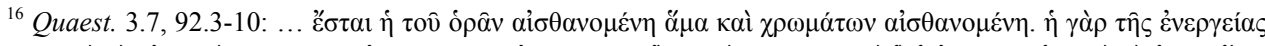

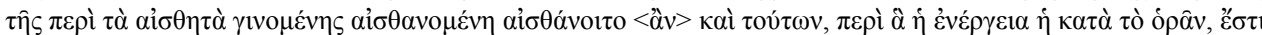

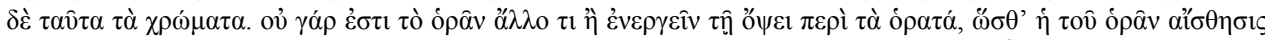

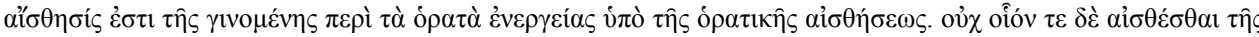

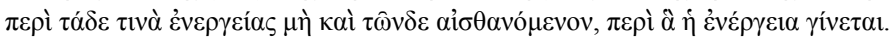


Alexander discusses at the end of Quaestiones 3.7 (see below, §4) - it would at most follow that we perceive the first-order objects extrinsically, since these two activities would still differ 'in being' ( $D A 3.2,425 \mathrm{~b} 27,426 \mathrm{a} 16-17) .{ }^{17}$ When Alexander assumes, then, that the first-order objects are perceived intrinsically in the higher-order perception, he is effectively making an independent assumption about the character of the awareness involved in perceiving that we perceive. It is not something that genuinely follows from the rest of the theory.

So Alexander thinks that whenever we perceive with any of the five senses, we perceive that we perceive, and in a very specific way: the accompanying perception is a continuous awareness of ourselves perceiving that includes an awareness of the first-order perceptible objects intrinsically as such.

\section{A moderate capacity reading}

The main body of Quaestiones 3.7 follows the first half of Aristotle's De anima 3.2 quite closely. Alexander begins from the opening dilemma, concerning whether we perceive that we see by the same aisthêsis or a different one. He then considers each of the arguments Aristotle offers, one concerning duplication, the other an infinite regress, followed by the aporia Aristotle raises and his two solutions. Alexander follows this with a brief discussion of the subsequent passage in Aristotle, which Alexander takes to shed light on how this awareness comes about. The parallels are straightforward:

$\begin{array}{lll}\text { Quaestiones } 3.7 & \text { DA } 3.2 & \\ 91.28-34 & 425 \mathrm{~b} 12-13 & \text { opening dilemma } \\ 92.1-13 & 425 \mathrm{~b} 13-15 & \text { duplication argument } \\ 92.13-20 & 425 \mathrm{~b} 15-17 & \text { infinite regress argument } \\ 92.20-23 & 425 \mathrm{~b} 17-19 & \text { aporia } \\ 92.23-27 & 425 \mathrm{~b} 20-22 & \text { first solution } \\ 92.27-31 & 425 \mathrm{~b} 22-25 & \text { second solution } \\ 92.31-93.22 & 425 \mathrm{~b} 25-426 \mathrm{a} 27 & \text { how it comes about }\end{array}$

To many ears, the details of Alexander's interpretation will sound unexceptionable or at least very familiar. For Alexander is the first, to my knowledge, to articulate the reading most popular today, something I have elsewhere labelled a moderate capacity reading. ${ }^{18}$

\footnotetext{
${ }^{17}$ Aristotle holds that it is only when $X$ and $Y$ are the same 'in being' that whatever can be said of $X$ can be said of $Y$ and vice versa; if they are only the same 'in number' (as these activities are), the predicates will be true of them extrinsically at best. See Soph. El. 24, 179a35-39; Phys. 3.3, 202b14-16.

${ }^{18}$ See V. Caston, 'Aristotle on consciousness', Mind 111 (2002) 751-815 (761-63).
} 
The issue turns on a systematic ambiguity that infects most, if not all, of Aristotle's formulations in the opening of De anima 3.2. The most central word in the passage, aisthêsis or 'perception', can be used for both:

a. The activity of perceiving;

$b$. The power or capacity to perceive.

The ambiguity of this term in the present context can hardly be doubted. Aristotle explicitly distinguishes these two senses later in the very same chapter and says that the ambiguity extends to all of the terms used for the five senses and for their objects (426a69). In fact, he excoriates his predecessors for not having taken this difference into account and cites it as the cause of their errors (426a20-27). Nor is this an isolated point. The distinction between a power and the activity it issues in is fundamental to the overall framework of Aristotle's psychology. His examination of perception in general in De anima 2.5 turns crucially on it (417a9-b16), as does his definition of the soul as a first actuality in De anima 2.1 - in fact, he appeals there to the example of sight as a clearer case of the same distinction he wishes to make in the case of the soul $(412 \mathrm{~b} 17-413 \mathrm{a} 3 ; \mathrm{cf}$. 412a22-b6; 2.2, 413b11-13).

The character and force of Aristotle's arguments in De anima 3.2 look very different depending on which sense one takes to be in play at each occurrence. Following Brentano, I have argued (see Caston, 'Aristotle on consciousness' (n.18, above)) that Aristotle's arguments make the best sense if construed primarily in terms of activities: that is, as concerned with whether perceiving that we see is a second activity, distinct from the original first-order activity of sight, or whether there is instead just one activity with (at least) two aspects, a first-order visual one and a higher-order reflexive one. Aristotle offers two arguments against the first option, objecting that when we perceive that we see, we would have two activities of perception directed toward the same first-order objects; and also that if a second activity were necessary, it would follow that there were infinitely many of them.

Most modern readers do not notice this ambiguity, much less take it into account. Like Alexander, they simply assume that the arguments concern the number of powers or capacities involved in perceiving that we see. So understood, the opening dilemma is whether there is a second sense responsible for perceiving that we see or whether the sense of sight on its own is sufficient. The subsequent arguments then claim that on the first option there would be two senses for perceiving colour; and that if two such senses were necessary, there would have to be infinitely many of them. But it is difficult to make sense of the actual wording of Aristotle's arguments, if we construe them consistently in terms of capacities. Consider the first two sentences when taken in this way:

Since we perceive that we see and hear, we must perceive that we see either by sight or by another [sense]. But then there will be the same [sense] for both sight and the colour that serves as its object, so that either there will be two [senses] of the same thing or the same [sense] will be of itself. ${ }^{19}$

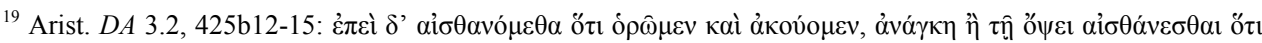

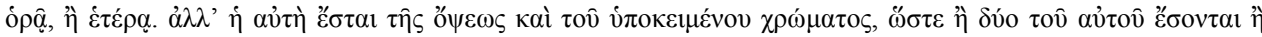

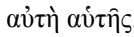


If taken literally, these lines would be asking whether a second sense perceives the power

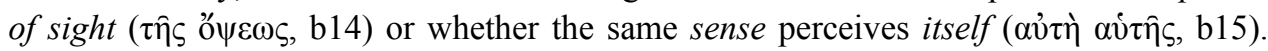
But it would be preposterous to claim that in perceiving that we see, what we perceive is the power to see, rather than the activity of seeing. So even though most commentators translate the passage this way, no one actually takes this rendering to mean what it says (something I have called an extreme capacity reading). Instead they temporize, by having Aristotle switch repeatedly between the two senses, even within a single sentence. On this more moderate reading, Aristotle argues that it is by sight ( $\tau \hat{\eta}$ o้ $\psi \varepsilon 1$, b13) that we have a perception of seeing ( $\tau \hat{\eta} \varsigma$ oै $\psi \varepsilon \omega \varsigma$, b14); and the way in which a sense will itself be of

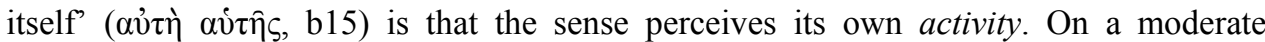
capacity reading, the arguments' conclusions concern the number of capacities, but it is their activities which serve as the objects of higher-order perceptions.

It would be reasonable at this stage to ask whether it is plausible to construe these terms as switching referent so quickly, even within a single phrase like 'itself of itself' ( $\alpha \dot{\tau} \hat{\eta} \alpha \dot{\tau} \tau \hat{\eta} s$, b15) where a reflexive pronoun is used, and whether we should be tied to a capacity reading in the first place. ${ }^{20}$ But however that may be, Alexander shows no signs of unease. Here is how he disambiguates the opening dilemma:

Does this accompanying perception arise in us through the same sense through which we have awareness of the perceptible object, so that it is by sight that we both see things seen and perceive ourselves seeing; or do we perceive visible objects by sight, but perceive seeing itself with some other [sense] $?^{21}$

In this sentence, he clearly distinguishes between the perceptual power through which $(\delta \mathrm{t}$ ' $\hat{\eta} \varsigma)$ we perceive an object and the awareness ( $\dot{\eta} \dot{\alpha} v \tau \dot{\imath} \lambda \eta \psi 1 \varsigma)$ that results, and then asks whether the same sense is responsible ( $\delta \dot{\alpha} \tau \hat{\eta} \varsigma \alpha \hat{v} \tau \hat{\eta} \varsigma \alpha \hat{\imath} \sigma \theta \dot{\eta} \sigma \varepsilon \omega \varsigma)$ for the accompanying, higher-order perception. He consistently distinguishes between the power of sight (ö $\psi 1 \varsigma$ ) and seeing ( $\delta \hat{\rho} \hat{v})$, both here and in the remainder of the discussion (91.33-34; 92.2, 6-8, 20-23). In each case, he makes the object of the higher-order perception an activity, and not the underlying capacity, just as a moderate capacity reading should.

But not even Alexander can avoid the ambiguity of these terms entirely. We thus find him alternating between perception understood as an activity and understood as a capacity in a single sentence (92.7-8):

... so that the perception ( $\left.\alpha{ }^{\prime} \sigma \theta \eta \sigma ı\right)$ ) of seeing is a perception ( $\alpha$ lo $\left.\sigma \eta \eta \sigma ı\right)$ ) of the occurrent activity concerning objects that can be seen due to the visual sense ( $\tau \hat{\eta} \varsigma$

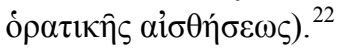

\footnotetext{
${ }^{20}$ This is one of the motivations for the alternative activity reading I offer in Caston, 'Aristotle on consciousness' (n.18, above).

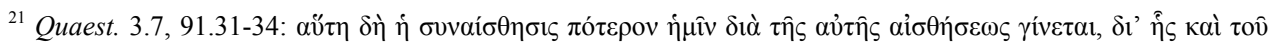

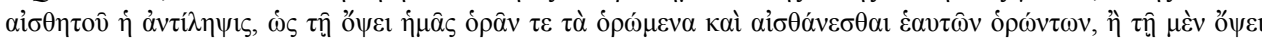

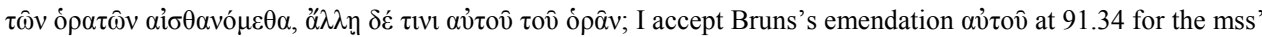
oủ $\tau \hat{n}$, which makes little sense. Bruns rightly refers to the parallel at 92.21 .

${ }^{22}$ For the Greek text, see n.16 above.
} 
The first two uses plainly refer to the act of perceiving, the last one explicitly to the capacity. He then reverts to the more regimented use of these terms he employed previously: on the

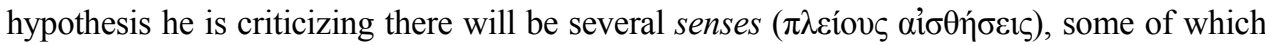
perceive external perceptible objects primarily ( $\alpha i \sigma \theta \alpha v o ́ \mu \varepsilon v \alpha \imath \alpha \hat{\tau} \tau \hat{\omega} v \pi \rho \circ \gamma \gamma \sigma u \mu \varepsilon v \omega \varsigma)$ and others which perceive the activities of the senses concerned with these objects ( $\tau \hat{\omega} \mathrm{V}$

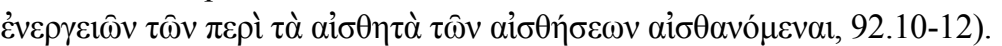

The same sort of vacillation in meaning occurs in the second argument. He begins by speaking about whether there is one sense which perceives ( $\dot{\eta} \alpha i \sigma \theta \alpha v o \mu \varepsilon \dot{v} \eta)$ and another

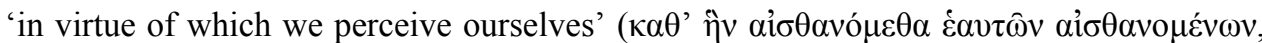
92.14-15). But he then goes on to use the same term to speak both of perceptions and senses in the ensuing regress:

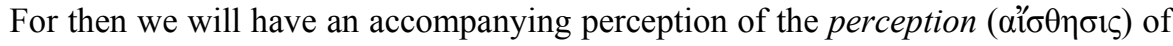

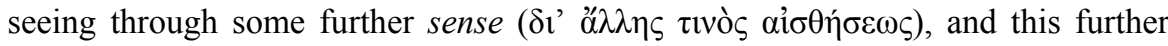

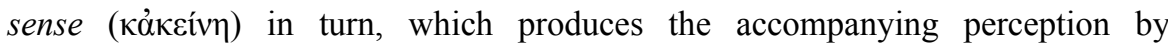

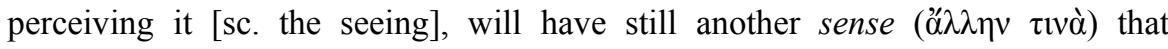
perceives [it]; and this will continue to infinity, which is completely absurd. The remaining alternative is that we perceive perceptibles and our activities concerning

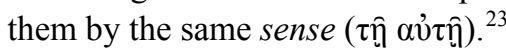

Alexander imagines two regresses, in effect, parallel to each other: first, a regress of activities, of ever higher-order perceptions directed at the perceptions at the previous level; and second, a regress of capacities, which individually underwrite the higher-order perceptions at each new level. But his conclusion addresses only the second regress: there must be a single capacity by which we have both higher- and lower-order perceptions (92.18-20).

What Alexander fails to recognize is that blocking the second regress does not block the first: there might still be a regress of higher-order perceptions, even if there is just a single capacity. Once he allows that a single capacity can support perceptions of different orders, with some directed at others - as his own considered view allows - it becomes reasonable to ask whether we must perceive every perception we have, regardless of order, with a distinct activity. The moderate capacity reading of the regress argument assumes this and Alexander nowhere questions it. But then Alexander is committed to a regress of activities too, even though there is only a single capacity, and this is surely equally absurd. If, on the other hand, he rejects this assumption and blocks the regress of activities directly, he thereby blocks the regress of capacities, without having to do anything further.

The broader context of Aristotle's De anima might explain why Alexander focuses on capacities. In the first chapters of De anima Book 3, Aristotle is busy counting capacities: he is concerned with whether higher perceptual functions require anything more than the five sense modalities discussed in Book 2. The general thrust of Aristotle's argument is that nothing more is required, either for perceiving common perceptibles, perceiving perceptibles extrinsic to a given sense or to all the senses, or discriminating between

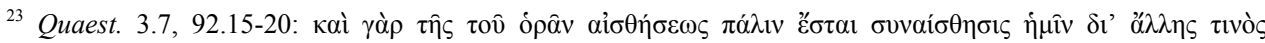

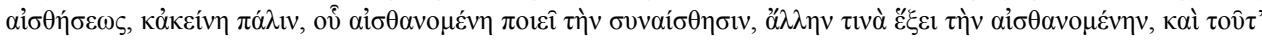

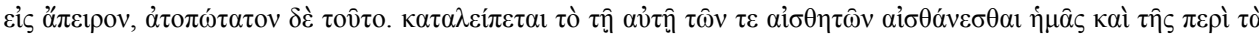

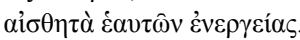


cross-modal perceptibles. On this reading, Aristotle is pushing the same line with regard to perceiving that we perceive: it is something we can do with the perceptual power itself whose activity is perceived. We do not have to postulate any further power than the five senses to which we are already committed.

What context does not explain is why Alexander fails to consider the apparent conflict between this claim and views Aristotle expresses elsewhere about the common sense, of which Alexander is fully aware. In De somno 2, Aristotle denies that we perceive that we see in virtue of sight. It is due instead to the common sense:

There is also a power that supervenes on all of them in common, by which one perceives that one is seeing and hearing, for it is surely not the case that one sees that one sees by sight. And it is certainly not the case that one discerns, or is even capable of discerning, that sweet things are different from pale ones by taste or by sight or by both together, but rather by a certain part common to all the sense organs. For there is a single sense and a single principal sense organ, but its being is different for the sense of each kind [of perceptible], for example, of sound and of colour. ${ }^{24}$

Alexander adopts virtually the same view in his own De anima:

We also perceive ourselves seeing, hearing, and perceiving with each sense by this common sense. For the person seeing perceives himself seeing and the person hearing perceives himself hearing, since we definitely do not perceive ourselves perceiving with any other power besides the <common $>$ sense. For we do not see that we see or hear that we hear, since seeing is not visible or hearing audible. Rather, it is the activity that belongs to the primary and fundamental sense, described as the 'common' sense, in virtue of which perceivers come to have an accompanying perception of perceiving. ${ }^{25}$

Neither Aristotle nor Alexander addresses how these two views are to be reconciled - if, indeed, they are to be reconciled at all. It is possible, with either author, that one view was discarded in favour of the other at some later stage. ${ }^{26}$ But it is also possible, at least in

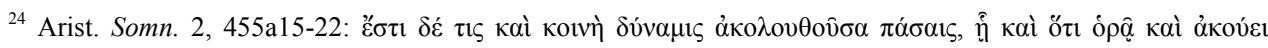

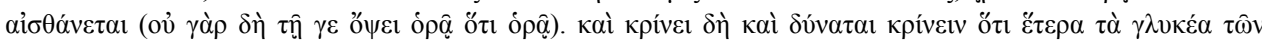

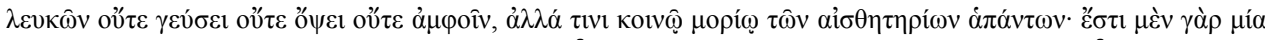

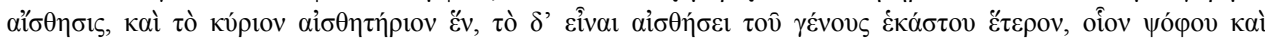
$\chi \rho \omega ́ \mu \alpha \tau o \zeta$. I would like to thank Charles Brittain for helpful discussion of the punctuation of the Greek.

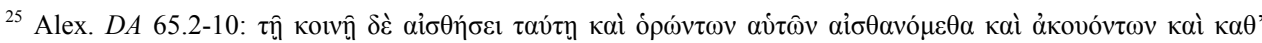

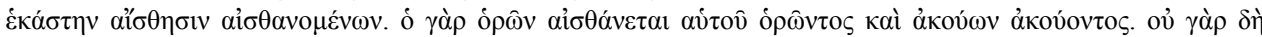

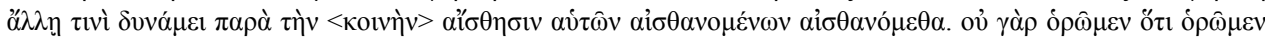

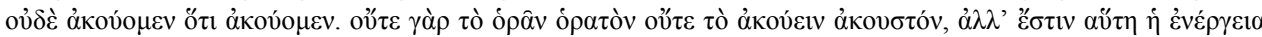

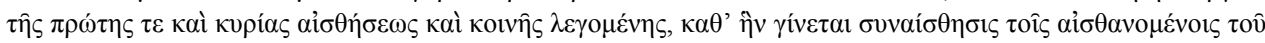

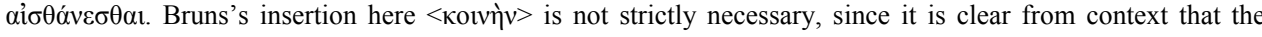
common sense is intended. But for just the same reason, it does not do any real harm either to include it in brackets.

${ }^{26}$ In Aristotle's case, some have argued that De somno expresses his mature view (I. Block, 'The order of Aristotle's psychological writings', American Journal of Philology 82 (1961) 50-77; I. Block, 'Three German commentators on the individual senses and the common sense in Aristotle's psychology', Phronesis: A Journal for Ancient Philosophy 9 (1964) 58-63, esp. p. 63), while others take this to be found in the De anima (A. Torstrik, Aristotelis De anima, Libri III (Berlin 1862) 166-67, note *). 
Aristotle's case, that both views should be understood as compatible. On this reading, the common sense would not be another sense distinct from the individual senses and so vulnerable to the objections raised at the beginning of De anima 3.2. Instead, it would be a power we have as a consequence of having other senses and possessed in common with

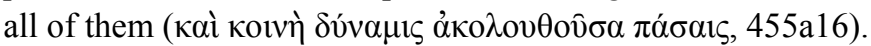

Some of these same gambits are available to Alexander. He certainly agrees that there is no sense distinct from the five individual senses (65.21-66.6), and that the common sense is shared by all the individual senses, just as the centre of a circle is shared by all of the radii extending from its periphery (63.6-64.11): it is 'one and the same power constituted from the

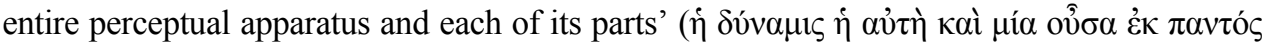

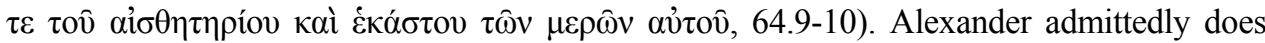
emphasize the difference between the organs belonging to the peripheral senses and the

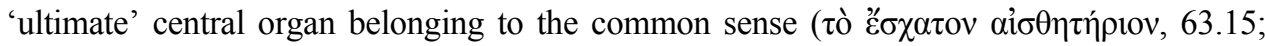
$64.8 ; 64.18 ; 96.31 ; 97.5,10 ;$ In Sens. 168.3). But he also thinks that all perception takes place, strictly speaking, in the ultimate sense organ: the only difference that matters is whether something is perceived in virtue of the generic power of perception, common to all the senses, or in virtue of one of its specific modalities.

This proposal certainly fits Alexander's claim in his own De anima that we do not see that we see, but only perceive that we see: the higher-order perception occurs solely in virtue of the generic power of perception, unlike the first-order perception, which takes place through a specific modality like sight. But Quaestiones 3.7 expressly denies this. In laying out the dilemma's two horns, Alexander states the alternative he ultimately prefers

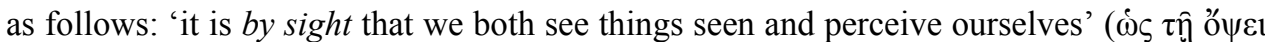

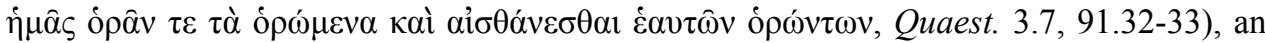

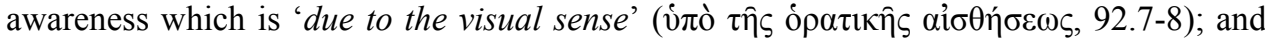
he concludes the discussion by saying that the accompanying perception 'also comes to

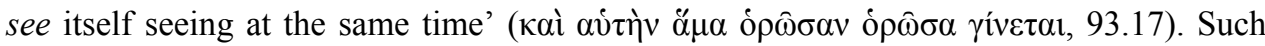
talk is precisely what triggers the subsequent aporia in Aristotle's De anima 3.2 about whether seeing itself is coloured, on the supposition that everything visible is coloured, a worry Alexander then attempts to solve by exploring the solutions originally offered by Aristotle (Quaest. 3.7, 92.23-31). Alexander's response in his own De anima, in contrast, is much sharper and cleaner: we do not see that we see precisely because seeing is not coloured, full stop ( $D A$ 65.6-8). Rather, we perceive that we see in virtue of the generic power alone (65.8-10). The approach in these two texts is thus fundamentally opposed.

One could try to defend the Quaestiones discussion by arguing that it is simply a draft for Alexander's lost commentary on Aristotle's De anima, or perhaps even an extract from it, and that as such it does not need to go beyond the bounds of the text in question, which does not mention the common sense; and as such it needn't express Alexander's own personal commitments either. But this cannot avoid the issue entirely. Given that Alexander is aware of the discrepancy in Aristotle's expressed views, and that he prefers one of them over the other, why doesn't he mention or address the difference explicitly in Quaestiones 3.7? The two treatments can be defended on lawyerly grounds. But philosophically a certain amount of candour is wanting. 


\section{How higher-order awareness comes about}

Perhaps the most interesting feature of Alexander's discussion is that he regards the subsequent passage of De anima 3.2 (425b26-426a26) as showing how this accompanying

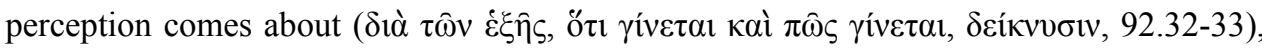
even though Aristotle does not mention higher-order awareness himself in this passage. He only argues that the activities of the perceptual power and the perceptible object are

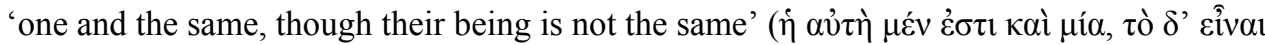

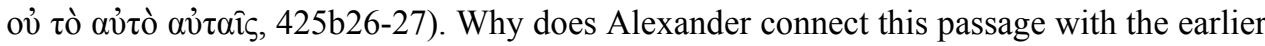
one, about perceiving that we see?

A natural suggestion, not offered by Alexander, is that this passage is a continuation of Aristotle's response to the aporia he raises in the earlier passage at 425b17. The worry can be stated succinctly: if we able to perceive that we are perceiving, then our perceiving must itself be perceptible; and if it is perceived by the same power used for the first-order objects, as Aristotle claims on a moderate capacity reading, then won't the perceiving itself be perceptible in the same way? Aristotle uses sight as his example. If:

1. We perceive that we see by sight (425b13-17), and;

2. To perceive by sight is just to see (b18);

3. Anything we see is either a colour or has a colour (b18-19),

then one might worry that:

4. 'What sees' ( $\tau$ ò ó $\rho \hat{\omega} v)$ - or, with Alexander, our seeing ( $\tau$ ò ó $\rho \hat{\alpha} v)^{27}$ - will itself be coloured (b19-20).

which seems obviously unacceptable and so would constitute a reductio ad absurdum of the position Aristotle has just been arguing for. His first response is to challenge premise (2): although we perceive darkness by sight, we do not see it, or at least not in the same way, by its being visible (b20-22). Aristotle does not develop this suggestion further, though, and neither does Alexander. But the accompanying perception cannot consist simply in noticing that the 'lights are on,' so to speak, if it also includes an awareness of the first-order objects perceived on each occasion, as Alexander insists. Aristotle's second response is entirely different: instead of questioning any of the premises, he reconsiders whether the conclusion might in some sense be acceptable after all. Perhaps 'what sees,' Aristotle says with laconic brevity, is

... in a way coloured, because each sense organ is able to receive the perceptible object without the matter. ${ }^{28}$

The subsequent lines could then be seen as a further explanation of this cryptic remark. If our seeing is 'one and the same' as the activity of colour, one might think, then seeing is in a way coloured and so something visible, something that can be seen, thus dissolving the

\footnotetext{
${ }^{27}$ This is how Alexander glosses the argument at 92.22-23: 'then seeing, if it is something that can be seen, is

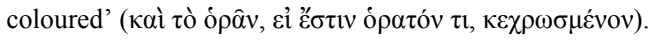

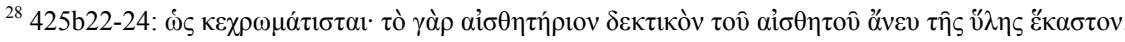


aporia. The suggestion that seeing is coloured is no longer an absurdity to be rejected, but a feature of the view. The activity of seeing would not be intrinsically coloured, of course, since it is only extrinsically the same as the activity of the coloured object - they still differ 'in being' (425b27, 426a16-17). But being extrinsically coloured is sufficient to make seeing something that can itself be seen, at least extrinsically, just as Aristotle thinks the sea or any other large body of water is. ${ }^{29}$

Alexander's strategy is bolder. It is not simply that our seeing can be seen. It must be seen, on every occasion. Initially, he just says that 'it makes sense' ( $\varepsilon \dot{\jmath} \lambda$ ó$\left._{\gamma} \omega \varsigma, 93.12\right)$ that there is always an accompanying perception. But he concludes his discussion by asserting

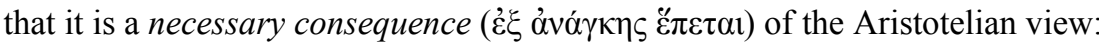

It is therefore a necessary consequence that every perceiver will also have an accompanying perception of himself perceiving because it a consequence of a sense's perceiving an external perceptible that it perceives itself at the same time as well. ${ }^{30}$

This claim goes far beyond anything that Aristotle says in De anima 3.2. At no point does Aristotle offer either argument or evidence for the claim that we perceive that we perceive (425b12). He simply asserts that we do and then argues from this assumption to the conclusion that it occurs by means of the same power (or even the same activity involved in the first-order activity, on my reading). Alexander reverses the order of explanation here, arguing from Aristotle's account of first-order perception to the conclusion that higher-order perception must occur.

What is the argument in Alexander's view that necessitates this conclusion? It is not a logical argument about sameness, so much as a physical or causal one. Perception, for Alexander as for Aristotle, is just a special case of change and modification. In general, a change or modification occurs in the thing changed or modified (93.2-4). So, too, in the case of perception:

The change originating from the perceptible object and the modification that comes about due to it, once it has come about in perception taken as a power, necessarily produces perception in activity. ${ }^{31}$

Alexander's language here suggests, at least at first glance, that the change and modification of the sense is distinct from perceiving, which is produced as a further effect. But if perception is analogous to the other cases, as Alexander clearly intends, then the change and

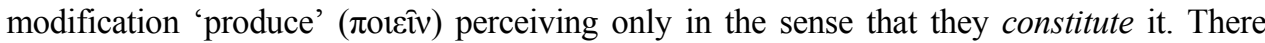
would be only one event, which is both a modification and a perceiving, such that having a modification in the relevant organs 'makes' a perceiver perceive.

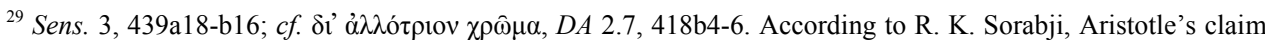
that seeing is in a way coloured should be understood precisely in this way, as being extrinsically perceptible. For discussion, see V. Caston, 'The spirit and the letter: Aristotle on perception', in Metaphysics, soul, and ethics: Themes from the work of Richard Sorabji, ed. R. Salles (Oxford 2005) 245-320 (250-51).

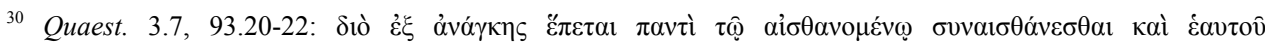

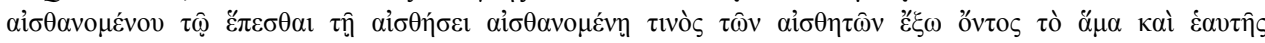

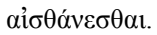

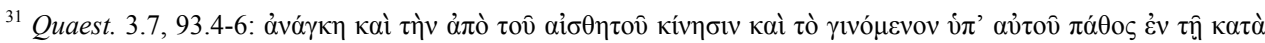

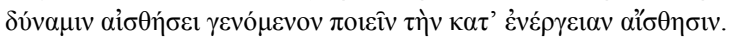


Perception differs from the other cases, however, in so far as the form of the perceptible object is received 'without the matter' (93.9-11). Given that this is the case, Alexander reasons,

$\ldots$ it makes sense that at the same time that we have a perception of perceptible

objects, we also have an accompanying perception in virtue of the same sense. ${ }^{32}$

As tantalizing as this suggestion is, however, it is hard to make good on it. Alexander does not explain why it makes sense or exactly how the two doctrines are supposed to be related. His subsequent remarks, moreover, do not invoke the manner in which the form is received at all, but merely the fact that it is received and that the sense possesses the form of the object as a result:

For there is an awareness of external perceptibles because [the sense] acquires ( $\lambda \alpha \mu \beta \alpha$ óveıv) the form from them; but the accompanying perception also in a way perceives [the awareness] for just this reason, namely, because the sense has $\left(\varepsilon^{\prime} \chi \varepsilon 1 v\right)$ the form in itself. For if seeing occurs in virtue of the acquisition of the perceptible's form (the argument is similar for the other senses too), by acquiring the form it sees and at the same time comes to see itself seeing. ${ }^{33}$

Acquiring or receiving the form is clearly sufficient for having the form. But why is having the form sufficient for perceiving the recipient or the recipient's activity? There is a crucial shift in objects: by receiving the form we become aware of the external objects from which we receive the form; but by having the form, we are also supposed to become aware of the form's presence in the perceiver and thus of the sense in activity.

The comparison with other causal cases does not help. Water in a kettle is warmed when it receives warmth from the fire; it now has warmth in itself as a result. But is the water is further warmed by having this warmth in it, so that it becomes even warmer? Plainly not. If it did, the kettle would continue to get warmer on its own, even after it had been taken off the flame - if left on its own, in fact, there would be no end to it, once started. And the same would be true for any other material alteration. One might more reasonably hold that by having warmth in it, the water conserves the warmth it has received, at least until an opposing factor intervenes. But this is not the result we were seeking either: in the case of perception, it would amount to nothing more than the persistence of the original perception, until other circumstances intervene (such as the appearance of a new object of perception, or a change in focus or attention, or various kinds of occlusion). There is nothing in the ordinary reception of form to suggest or explain the crucial shift in object. Nor does the possession of a form explain this. If it did, Aristotle could not object, as he does, to the idea that we always perceive our own sense organs (DA 2.5, 417a2-9; cf. Sens. 2, 437a26-29). For the sense

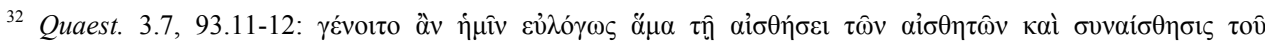

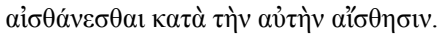

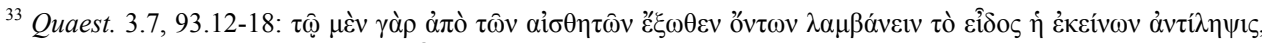

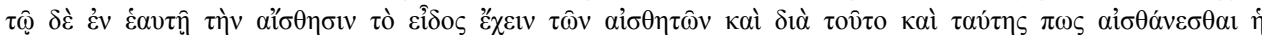

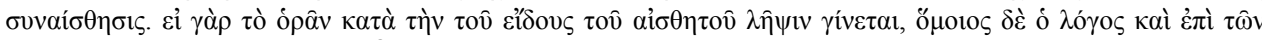

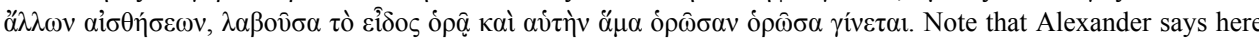
that the seeing sees itself: see discussion above, pp. 41-42. 
organs always possess certain perceptible qualities of their own. The reception and possession of a form is not enough on its own.

This takes us back to the original thought that what matters in the case of perception is the fact that form is received without the matter, that it is this difference that makes the difference. But how exactly is this supposed to secure a reflexive awareness of the perceiving itself? Perhaps the idea is this. In perception, we do not merely receive the forms of external objects, we become aware of them as a result - perceiving is an intentional state, which is directed at the perceptible object acting on the sense. And then we might invoke Aristotle's claim that the activity of the object is 'one and the same' as the activity of the sense perceiving it to arrive at an awareness of the latter as well. This is the strategy suggested, at any rate, by Aryeh Kosman's interpretation of the passage in Aristotle:

For given that the activity of the object of perception as such is the same as the activity of perception itself, there must be a single awareness of them both. ${ }^{34}$

On this view, it is not the sameness of activities by itself that matters, since that is something that holds for causal interactions between agents and patients quite generally. The peculiar result we obtain here is due to the fact that in receiving form without the matter, an intentional state is directed at one of these activities as its object. The sameness of activities then gets us to reflexive awareness, of the activity of perception being directed at itself as well.

Alexander should resist this inference, though. For us, the snag is that it involves substitution into a non-extensional context: if I perceive something as $F$, that also happens to be a $G$, it does not follow that I perceive it as a $G$. For Aristotle and Alexander, the inference is equally problematic, but the diagnosis is different. Inferences like Kosman's commit what is traditionally known as the 'fallacy of accident.' Sameness for Aristotle and Alexander is not identity. Even though the activity of the perceptible object and the perceptual power are the one and the same 'in number,' they differ in being (ovoía, Eivol); and so they are the same only extrinsically or 'accidentally.' But then according to Aristotle it does not follow that what is said of one can be said of the other. ${ }^{35}$ So even if the activity of the perceptible object, rather than the perceptible object itself, were perceived - a questionable assumption and one that Alexander himself rejects, as we shall see - it still would not follow that the activity of the sense would thereby be perceived, despite their being 'one and the same.' Kosman's inference cannot be the basis of Alexander's argument.

\section{Higher-order understanding \& higher-order awareness}

Alexander recognizes the difficulty elsewhere. In his De anima, he appeals to a similar doctrine to explain how the understanding (vov̧ $)$ can understand itself:

\footnotetext{
${ }^{34}$ See L. A. Kosman, 'Perceiving that we perceive: On the soul III, 2', The Philosophical Review 84 (1975) 499-519 (514); emphasis mine.

${ }^{35}$ For references to Aristotle's discussion of the fallacy, see n.17 above. For discussion of the distinction between sameness in number and sameness in being, see the important papers by G. Matthews, 'Accidental unities', in Language and logos: Studies in ancient Greek philosophy presented to G. E. L. Owen, ed. M. Schofield , M. C. Nussbaum (Cambridge 1982) 223-40; F. A. Lewis, 'Accidental sameness in Aristotle', Philosophical Studies 42 (1982) 1-36; F. A. Lewis, Substance and predication in Aristotle (Cambridge 1991) chapters 3-5.
} 
Since the understanding in activity is nothing other than the form that is understood, as was shown to be the case with perception as well, the dispositional understanding $\ldots$ at this stage is also able to understand itself. ${ }^{36}$

Alexander claims earlier in the treatise that perception, as an activity, just is the perceptible form's coming to be without the matter in the perceptive power. ${ }^{37}$ But he does not use this doctrine to argue for higher-order perception there; nor does he refer back to it later when he does discuss higher-order perception (65.2-10; see above, p. 41). So his explanation of how self-understanding comes about is without parallel in the treatise:

For [the understanding] becomes and is the very thing it can understand by understanding it, whenever it understands: it understands the understandable form primarily and intrinsically, but understands itself extrinsically, because it has this characteristic extrinsically, namely, that it becomes that which it understands whenever it understands. ${ }^{38}$

Here Alexander draws two crucial distinctions. The first is between the primary act of understanding, which is directed at its first-order objects, and the higher-order understanding of this very activity of understanding them. This distinction is reminiscent of the one Aristotle draws in Metaphysics $\Lambda 9$ between attitudes such as perception, knowledge, belief, and thought being directed at first-order objects and their being directed at themselves 'on the side' ('́) $\pi \alpha \rho \varepsilon \varepsilon^{\prime} \gamma(\omega) .{ }^{39}$ Only in God's case is there an understanding that is directed at itself primarily (1074b33-34).

The second distinction, though, is more important for our purposes here. Alexander contrasts what is understood intrinsically ( $\kappa \alpha \theta^{\prime} \alpha$ vì̀v) and what is understood extrinsically

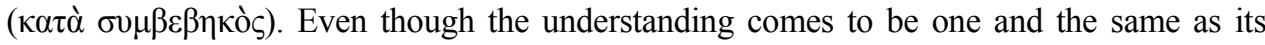
objects, they differ in being and so are not identical in any strict sense: what it is to be each, what each is intrinsically, is never the same. The understanding thus becomes the same as its object only extrinsically and for a time. ${ }^{40}$ From this, Alexander concludes that the activity of understanding can be understood only extrinsically. That is, we understand the activity of understanding only because it is extrinsically the same as a first-order object that we understand primarily and intrinsically - the activity of understanding literally happens to be $(\sigma u \mu \beta \varepsilon \beta \eta \kappa \varepsilon ́ v \alpha l)$ the same as the first-order object we understand at that moment. Compare Alexander's account of extrinsic perception. In his view, certain kinds of things - like the

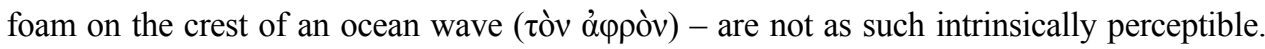
They are extrinsically perceptible, though, because they are extrinsically the same as things

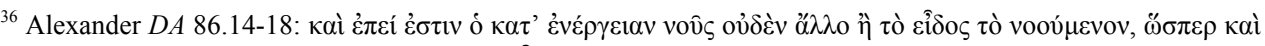

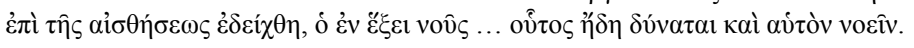

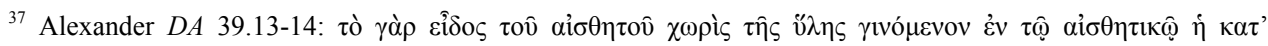

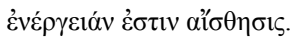

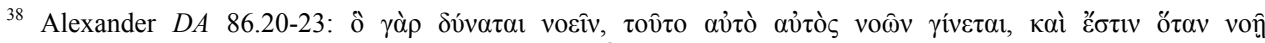

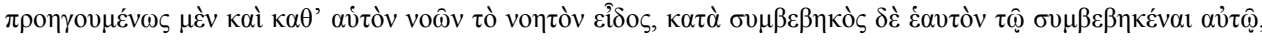

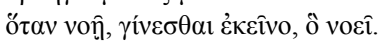

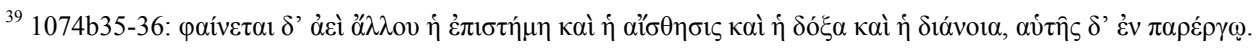

${ }^{40}$ Initially, while in potentiality, they are relatives, but they cease to be such when they coalesce together in activity (86.23-26).
} 
that are intrinsically perceptible. ${ }^{41}$ The fact, therefore, that the understanding is the extrinsically same as its object allows it to be an object of understanding too, at least extrinsically, and it cannot be understood in any more direct way. On Alexander's view, then, human self-understanding is a fairly weak and indirect form of higher-order cognition, which is entirely parasitic on our understanding of the first-order objects of understanding.

A few lines later, however, Alexander goes on to deny that this sort of extrinsic sameness results in self-awareness in the case of perception:

The understanding in activity, then, understands itself, because it becomes the very thing it understands, since it understands the forms separate from matter. For it does not understand this specific object [lit. the 'this'], but rather what it is to be this specific object, as stated above. Perception in activity, in contrast, is not said to perceive itself in a similar way, even though it too receives the forms of perceptibles, because it perceives the things it perceives as being in matter - since perception is of this specific object - but it does not itself become the same as the perceptible, because it does not receive the form as matter. For perception has cognition of enmattered perceptible forms in one way and the understanding in another. ${ }^{42}$

Perception is like understanding in the following respect: in both cases, the cognitive activity is one and the same as the form of the object, which is received without the matter. But they differ with regard to the kinds of things that can serve as their objects. In the case of the understanding, the object just is the form that is received. In perception, on the other hand, the form is distinct from the object of cognition: what we perceive is not the form of the object itself or the resulting activity, but the specific concrete object, that is, the instantiation of the form in a given quantum of matter. But then our perceptual activity is not one and the same as its object and so there is no longer the link that can take us from the first-order object of perception to a higher-order awareness of itself. Hence, we do not perceive our own perceptual activity simply because we perceive concrete objects. In his view, we understand the activity of understanding precisely because there is no difference between the object of understanding and the form we receive. Our understanding becomes one and the same as the actual object of understanding itself. The explanation of self-perception in the Quaestiones turns simply on sameness and as such

\footnotetext{
${ }^{41}$ Alexander $D A$ 41.6-10: 'For example, if someone were to say that foam is perceptible, it would be because foam happens to be white, which is perceptible. So things said to be perceptible in this way are not perceptible at

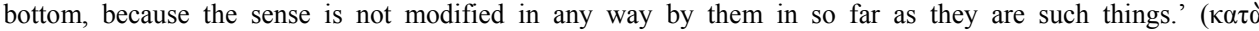

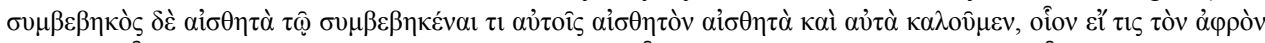

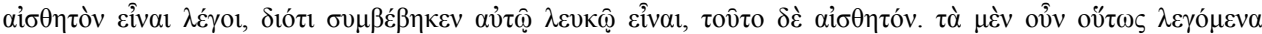

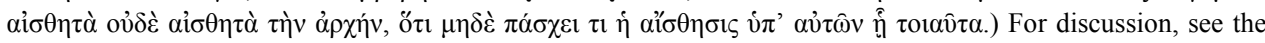
notes on 41.6-8 and 41.8-10 in V. Caston, Alexander of Aphrodisias: On the soul, Part I: Soul as form of the body, parts of the soul, nourishment, and perception, Ancient Commentators on Aristotle Series (London forthcoming).

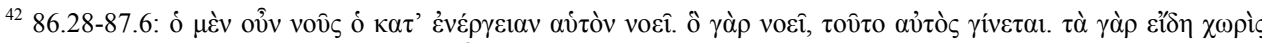

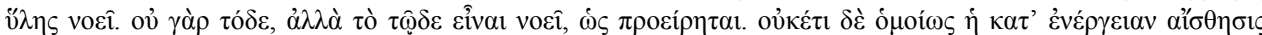

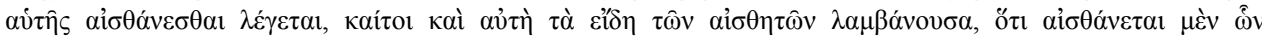

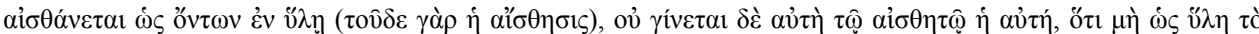

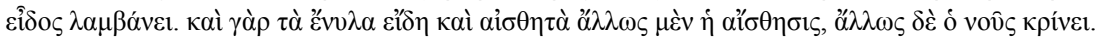


applies equally to perception and understanding. In the De anima, in contrast, it turns on a point of disanalogy in their objects and so applies to the understanding alone.

It is striking that in his De anima, Alexander does not argue that we perceive that we perceive because of how perceptual activity arises, as he does in his exegesis of Aristotle in Quaestiones 3.7. This leaves us with a puzzle. Why, in Alexander's own considered view, must we perceive that we perceive and how do we do it? Saying that it is with the same power or sense that is employed in the first-order perception does not furnish us with the missing details about how or why this activity is generated. Nor can we get any further with the qualification that we achieve this only in virtue of the general or common power which this sense shares with the other senses, that is, the common sense. What we would like to know is whether Alexander himself believes that other Aristotelian doctrines entail that we perceive that we perceive and explain how it is possible. It may be significant that in his treatment of the issue in his own De anima, he quietly drops the stronger claims of the Quaestiones. This would not be unreasonable, since Aristotle makes no such claim himself in his De anima. He claims there that we have such higher-order perception, and in other places like Nicomachean Ethics 9.9, he even claims that it occurs in every instance of perceiving. But Aristotle never tries to argue why this is so, much less derive it from his other doctrines. It is, he believes, simply a fact about consciousness we ought to accept.

University of Michigan 